\title{
EMERGÊNCIA DE PLÂNTULAS DE Zizyphus joazeiro MART (RHAMNACEAE) EM FUNÇÃO DE SUBSTRATOS ${ }^{1}$
}

\author{
Joel Martins Braga Júnior², Riselane de Lucena Alcântara Bruno ${ }^{3}$ e Edna Ursulino Alves ${ }^{3}$
}

\begin{abstract}
RESUMO - O juazeiro é uma planta muito importante para a região semiárida do Nordeste, mantendo-se sempre verde e constituindo fonte de alimentos para os animais na época de escassez de chuvas. Devido ao fato de a espécie se propagar principalmente por unidades de dispersão (endocarpo + semente), este estudo teve como finalidade avaliar diferentes tipos de substratos para emergência de plântulas de juazeiro. O experimento foi conduzido em casa de vegetação, no Centro de Ciências Agrárias da Universidade Federal da Paraíba, em Areia, PB. Os substratos utilizados foram: Plugmix ${ }^{\circledR}$, vermiculita, terra vegetal, terra vegetal + esterco bovino (nas proporções de 3:1, 1:1 e 1:3), terra vegetal + areia (nas proporções de 3:1, 1:1 e 1:3), areia, areia + pó de madeira (nas proporções de 3:1, 1:1 e 1:3), pó de madeira, areia + raspa de madeira (nas proporções de 3:1, 1:1 e 1:3), raspa de madeira, areia + esterco bovino (nas proporções de 3:1, 1:1 e 1:3). Através de avaliações diárias, determinaram-se as seguintes características: emergência, índice de velocidade de emergência, comprimento e massa seca de plântulas. Para emergência de plântulas, o substrato mais eficiente foi terra vegetal, e, quanto ao vigor, os maiores valores foram obtidos nos substratos Plugmix ${ }^{\circledR}$, terra vegetal + esterco bovino, nas proporções de 3:1 e 1:1 e areia.
\end{abstract}

Palavras-chave: Juazeiro, Vigor e Espécie florestal.

\section{EMERGENCE OF Zizyphus joazeiro MART. (RHAMNACEAE) SEEDLINGS DEPENDANT ON SUBSTRATES}

\begin{abstract}
The juazeiro is a very important plant for the northeast half-barren semi-arid region, always remaining green, and being food source for the animals at during droughts. Due to the fact that the species mainly propagates by dispersion units (endocarps + seeds), the present study had as its purpose the evaluation of different types of substrates for the emergence of juazeiro seedlings. The experiment was carried out in a greenhouse at the Centro de Ciências Agrárias of the Universidade Federal da Paraíba, in Areia-PB, Brazil. The substrates used were: Plugmix ${ }^{\circledR}$, vermiculite, vegetal soil, vegetal soil + cattle manure (in ratios of 3:1,1:1 and 1:3), vegetal soil + sand (in ratios of 3:1,1:1 and 1:3), sand, sand + wood dust (in ratios of 3:1, 1:1 and 1:3), wood dust, sand + shaved wood (in the ratios of 3:1, 1:1 e 1:3), scraped wood, and sand + cattle manure (in the ratios of 3:1,1:1 and 1:3). Through daily evaluations, the following characteristics had been determined: emergence, index of the speed of emergence, and the length and dry mass of the seedling. For the emergence of seedlings, the most efficient substrate was vegetal soil, and in terms of vigor, the greatest values were obtained in the Plugmix ${ }^{\circledR}$, vegetal land + cattle manure in the ratios of 3:1 and 1:1 and sand substrates.
\end{abstract}

Keywords: Juazeiro, Vigor and Forest species.

\section{INTRODUÇÃO}

O juazeiro (Zizyphus joazeiro Mart.) é uma planta muito importante para a região semiárida do Nordeste, a qual se mantém sempre verde e constitui fonte de alimento para os animais na época de escassez de chuvas. A árvore pode alcançar até $10 \mathrm{~m}$ de altura, possui copa grande, proporcionando boa sombra, e suas sementes apresentam dormência devido à alta resistência do endocarpo (MENDES, 1996; LORENZI, 2002).

Os substratos têm sua utilização mundial incrementada anualmente por proporcionarem melhores condições físicas, químicas e biológicas ao

\footnotetext{
${ }^{1}$ Recebido em 10.01.2008 e aceito para publicação em 02.03.2010.

${ }^{2}$ Programa de Pó-Graduação em Agronomia na Universidade Federal da Paraíba, UFPB, Brasil. E-mail: <joel-braga@hotmail.com>.

${ }^{3}$ Universidade Federal da Paraíba, UFPB, Brasil. E-mail: <lane@cca.ufpb.br> e <ednaursulino@cca.ufpb.br>.
} 
desenvolvimento das plantas (KÄMPF, 2001; BATAGLIA e ABREU, 2001), cujos materiais podem ser de origem vegetal (xaxim, esfagno, turfa, carvão, fibra de coco e resíduos de beneficiamento, como tortas, bagaços e cascas); mineral (vermiculita, perlita, granito, calcário, areia, cinasita) e sintética (lã-de-rocha, espuma fenólica e isopor) (GONÇALVES, 1995).

O substrato é o suporte físico para a germinação das sementes e também o local onde as plantas se fixam e retiram água e nutrientes, desse modo exercendo influência significativa na arquitetura do sistema radicular, no estado nutricional das plantas (SPURR e BARNES, 1973) e no movimento da água até a planta (ORLANDER e DUE, 1986), bem como oferecer adequada aeração às raízes. Assim, o substrato ideal, de acordo com Melo (1989), deve ser de baixa densidade, rico em nutrientes, ter composição química e física uniformes, elevada capacidade de troca iônica, boa capacidade de retenção de umidade, aeração e drenagem, boa coesão entre as partículas e aderência às raízes e ser, preferencialmente, estéril. Schmitz et al. (2002) destacaram, também, a porosidade, a água disponível, o $\mathrm{pH}$, a salinidade e o teor de matéria orgânica como importantes fatores na qualidade de substratos.

A escolha do substrato para testes de germinação e vigor é efetuada em função da facilidade e eficiência do uso desse e do tipo de semente da espécie vegetal a ser analisada, considerando algumas de suas características, como o tamanho das sementes, a necessidade de água e luz, a facilidade da contagem e a avaliação das plântulas (SOUZA, 1983; POPINIGIS, 1985). Substratos alternativos de origem vegetal têm sido recomendados para produção de mudas e cultivo de plantas envasadas (SOUZA, 2001), em substituição ao solo.

O esterco de animais é um exemplo de substrato orgânico que é bastante utilizado para produção de mudas de espécies frutíferas (SEDIYAMA et al., 2000), que misturado a outros materiais, a exemplo da vermiculita (COSTA et al., 2002), reduz a densidade média da mistura, melhorando suas condições de aeração e drenagem (GONÇALVES et al., 2000).

Atualmente, existe grande preocupação por parte dos pesquisadores e analistas de sementes, sobretudo os que trabalham com espécies florestais, em conduzir estudos que forneçam informações sobre a qualidade das sementes, especialmente no que diz respeito à padronização, agilização, aperfeiçoamento e estabelecimento dos métodos de análise. Nas Regras para Análise de Sementes (BRASIL, 1992) existem prescrições para a condução do teste de germinação de grande número de espécies cultivadas, no entanto as espécies florestais nativas ainda são pouco pesquisadas.

Para sementes de espécies florestais, alguns substratos têm sido recomendados para condução de testes de emergência, a exemplo de areia para Mimosa caesalpiniaefolia Benth. (SANTOS et al., 1994) e Hancornia speciosa Gomes (NOGUEIRA et al., 2003), solo + terriço de mata + vermiculita para Eugenia dysenterica DC. (SOUZA et al., 2001), solo + fibra de coco + plantmax ${ }^{\circledR}$ para Diospyros ebenaster Retz (OLIVEIRA et al., 2006), areia e vermiculita para Erythrina velutina Willd (ALVES et al., 2008).

Pelo exposto, este trabalho foi desenvolvido com a finalidade de avaliar diferentes tipos de substratos para a emergência de plântulas de juazeiro.

\section{MATERIAL E MÉTODOS}

O trabalho foi realizado em ambiente protegido pertencente ao Departamento de Fitotecnia, do Centro de Ciências Agrárias, da Universidade Federal da Paraíba, na cidade de Areia, PB.

Os frutos de juazeiro foram colhidos diretamente de cinco árvores-matrizes localizadas no Município de Barra de Santa Rosa, PB, em seguida levados para o Laboratório de Análise de Sementes do Centro de Ciências Agrárias (UFPB), onde foram despolpados manualmente, restando parte do fruto, o endocarpo que ficou aderido ao tegumento da semente, sendo submetidos à fermentação por cinco dias para a retirada da mucilagem. Decorrido esse período, os frutos foram lavados com água corrente, sobre peneira de arame, e postos para secar à sombra por cinco dias.

Para avaliação da emergência de plântulas e vigor de unidades de dispersão de juazeiro, foram avaliados 21 substratos, os quais se encontram descritos na Tabela 1 e, para as misturas, adotaram-se volumes iguais em litros, em quatro repetições de 25 unidades de dispersão escarificadas com lixa d’água número 80, na posição oposta ao hilo e semeadas em bandejas plásticas. As características avaliadas são descritas a seguir: 
Tabela 1 - Substratos utilizados para testes de emergência e vigor de sementes de juazeiro. Table 1 - Substrates used for the emergence and vigor test of Zizyphus joazeiro seeds.

\begin{tabular}{|c|c|c|}
\hline TRAT. & Substratos & Abreviações \\
\hline 1 & Plugmix ${ }^{\circledR}$ & Plugmix \\
\hline 2 & Vermiculita & Verm \\
\hline 3 & Terra vegetal & TV \\
\hline 4 & Terra vegetal + esterco bovino na proporção de 3:1 & $\mathrm{TV}+\mathrm{EB} 3: 1$ \\
\hline 5 & Terra vegetal + esterco bovino na proporção de $1: 1$ & TV+EB $1: 1$ \\
\hline 6 & Terra vegetal + esterco bovino na proporção de $1: 3$ & TV+EB $1: 3$ \\
\hline 7 & Terra vegetal + areia na proporção de 3:1 & TV+AR 3:1 \\
\hline 8 & Terra vegetal + areia na proporção de $1: 1$ & TV+AR 1:1 \\
\hline 9 & Terra vegetal + areia na proporção de $1: 3$ & TV+AR 1:3 \\
\hline 10 & Areia lavada & AR \\
\hline 11 & Areia + pó de madeira na proporção de 3:1 & $\mathrm{AR}+\mathrm{PM} 3: 1$ \\
\hline 12 & Areia + pó de madeira na proporção de $1: 1$ & $\mathrm{AR}+\mathrm{PM} 1: 1$ \\
\hline 13 & Areia + pó de madeira na proporção de $1: 3$ & $\mathrm{AR}+\mathrm{PM} 1: 3$ \\
\hline 14 & Pó de madeira & $\mathrm{PM}$ \\
\hline 15 & Areia + raspa de madeira na proporção de $3: 1$ & $\mathrm{AR}+\mathrm{RM} 3: 1$ \\
\hline 16 & Areia + raspa de madeira na proporção de $1: 1$ & AR+RM 1:1 \\
\hline 17 & Areia + raspa de madeira na proporção de $1: 3$ & AR+RM 1:3 \\
\hline 18 & Raspa de madeira & RM \\
\hline 19 & Areia + esterco bovino na proporção de $3: 1$ & AR+EB 3:1 \\
\hline 20 & Areia + esterco bovino na proporção de $1: 1$ & AR+EB 1:1 \\
\hline 21 & Areia + esterco bovino na proporção de $1: 3$ & $\mathrm{AR}+\mathrm{EB} 1: 3$ \\
\hline
\end{tabular}

Emergência - Foi conduzida em casa de vegetação, sem controle de temperatura e umidade relativa do ar, sendo utilizadas 100 unidades de dispersão por tratamento, divididas em quatro subamostras de 25. As contagens do número de plântulas emergidas iniciaram-se aos 13 dias e estenderam-se até os 90 dias após a semeadura. O critério utilizado foi o de plântulas normais, que apresentavam as estruturas essenciais perfeitas (BRASIL, 1992), sendo os resultados expressos em porcentagem.

Índice de velocidade de emergência (IVE) - Foram realizadas contagens diárias, dos 13 aos 90 dias, de plântulas normais, e o índice foi calculado conforme a fórmula proposta por Maguire (1962).

Comprimento da raiz principal e da parte aérea das plântulas - No final do teste de emergência, a raiz principal e a parte aérea das plântulas normais de cada repetição foram medidas com o auxílio de uma régua graduada em centímetros, sendo os resultados expressos em centímetro por plântula.

Massa seca das raízes e da parte aérea das plântulas - Após a contagem final no teste de emergência, separaram-se, com o auxílio de tesoura, as raízes e a parte aérea das plântulas anteriormente medidas, as quais foram submetidas à secagem, em estufa regulada a $65{ }^{\circ} \mathrm{C}$, até atingirem peso constante.
O delineamento experimental utilizado foi o inteiramente ao acaso, mediante sorteio, constando de 21 tratamentos, em quatro repetições de 25 unidades de dispersão de juazeiro. Os dados foram submetidos à análise de variância para comparar o efeito dos substratos no vigor das unidades de dispersão de juazeiro e as médias, comparadas pelo teste de Scott-Knott a 5\% (BORGES e FERREIRA, 2003). O software empregado foi o SAEG 2000.

\section{RESULTADOS E DISCUSSÃO}

De acordo com os dados da Figura 1, observa-se que o substrato 3 (terra vegetal) destacou-se dos demais com maior percentual de emergência, seguido do substrato 4 (terra vegetal + esterco bovino na proporção de 3:1), provavelmente pelo fato de reter mais umidade e calor, acelerando, assim, todo o processo metabólico da semente, que culmina com a germinação. O substrato terra vegetal misturado à vermiculita também foi recomendado por Moniz-Brito e Ayala-Osuña (2005) para a produção de mudas de Zizyphus joazeiro Mart. As menores porcentagens de emergência foram obtidas quando as unidades de dispersão foram semeadas nos substratos 11,12 e 13 (areia + pó de madeira na proporção de $3: 1,1: 1$ e $1: 3$, respectivamente), pelo fato de neles a retenção de água ser deficiente.

Revista Árvore, Viçosa-MG, v.34, n.4, p.609-616, 2010 


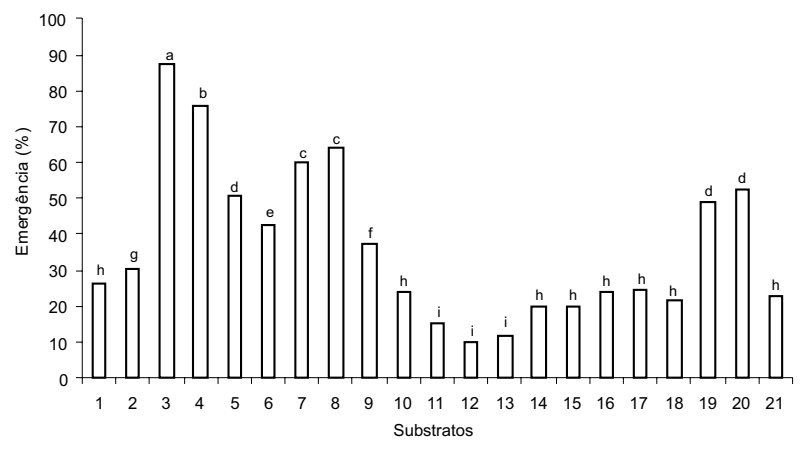

Médias seguidas da mesma letra não diferem estatisticamente entre si, pelo teste de Scott-Knott, $\mathrm{p}<0,05$. F - 117,544**; CV (\%) - 6,854.

Figura 1 - Emergência de plântulas de juazeiro oriundas de unidades de dispersão semeadas em diferentes substratos.

Figure 1 -Emergence of Z. joazeiro seedlings originating from dispersion units sown in different substrates.

Segundo Laviola et al. (2006), a emergência das plântulas pode acontecer em qualquer material que proporcione reserva de água suficiente para o processo germinativo, entretanto os resultados podem ser variados de acordo com cada metodologia e/ou substrato ou mistura utilizada.

Nas Regras para Análise de Sementes (BRASIL, 1992) não há recomendação de uso para a vermiculita, no entanto, segundo Figliolia et al. (1993), ela vem sendo recomendada como excelente substrato para testes de germinação e vigor de sementes de grandes dimensões e de formato arredondado, pelo fato de permitir o desenvolvimento mais adequado de plântulas durante o teste de germinação, em função do maior contato entre as sementes e o substrato.

Nos testes realizados com unidades de dispersão de juazeiro, a vermiculita não obteve, porém o êxito esperado. Resultados similares foram encontrados por Bezerra et al. (2004) com sementes de Moringa oleifera Lam., as quais não germinaram bem no substrato vermiculita._Scalon et al. (2003) verificaram que o substrato areia não foi adequado para germinação de sementes de sibipiruna (Caesalpinia pelthophoroides Benth). No entanto, Iossi et al. (2003) encontraram resultados diferentes quando trabalharam com sementes de tamareira-anã (Phoenix roebelenii O’Brien) e constataram que o substrato areia, juntamente com serragem e esfagno, proporcionaram as maiores porcentagens de germinação.
Os resultados referentes à influência dos substratos no índice de velocidade de emergência (IVE) de unidades de dispersão de juazeiro encontram-se na Figura 2. Analisando os dados, verificou-se que os substratos $3,4,7,8$ e 10 (terra vegetal, terra vegetal + esterco bovino e terra vegetal + areia, ambos na proporção de 3:1, terra vegetal + areia na proporção de 1:1 e areia lavada, respectivamente) foram responsáveis pelo maior vigor. Pode-se observar que os maiores índices de velocidade de emergência ocorreram nos substratos que continham maiores quantidades de terra vegetal. Tais resultados podem ser atribuídos à cor escura do substrato, a qual permite absorver mais energia solar, fornecendo a melhor temperatura para o desencadeamento do processo germinativo.

O substrato areia, segundo Scalon et al. (2003), proporcionou baixos índices de velocidade de germinação em sementes de sibipiruna (Caesalpinia pelthophoroides Benth.). Entretanto, Nogueira et al. (2003) constataram que o referido substrato proporcionou os maiores índices de velocidade de germinação de sementes de mangabeira (Hancornia pubescens Nees e Mart.), em que esses autores atribuíram o resultado às características de porosidade e esterilidade do substrato areia. Machado et al. (2002) também verificaram a eficiência do substrato areia na velocidade de germinação de sementes de ipê-amarelo (Tabebuia serratifolia (Vahl) Nicholson).

Quanto aos dados médios do comprimento da raiz primária (Figura 3), os maiores valores foram expressos quando se utilizaram os substratos 1, 2, 5, 10, 11, 15, 16, 17 e 18 (Plugmix ${ }^{\circledR}$, vermiculita, terra vegetal + esterco

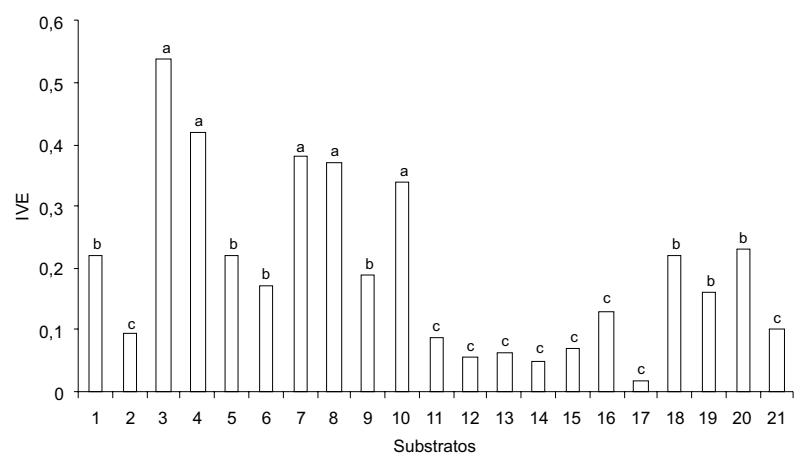

Figura 2-Índice de velocidade de emergência (IVE) de plântulas de juazeiro oriundas de unidades de dispersão semeadas em diferentes substratos.

Figure 2 - Index of speed of emergence (ISE) of Z. joazeiro seedlings originating from dispersion units sown in different substrates. 


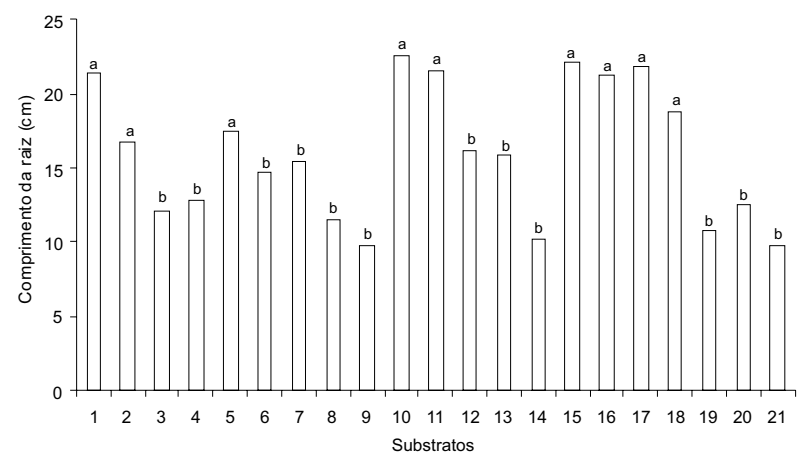

Médias seguidas da mesma letra não diferem estatisticamente entre si, pelo teste de Scott-Knott, p<0,05. F - 5,906**; CV (\%) - 23,375.

Figura 3 - Comprimento da raiz primária de plântulas de juazeiro oriundas de unidades de dispersão semeadas em diferentes substratos.

Figure 3-Length of the primary root of the Z.joazeiro seedling originating from dispersion units sown in different substrates.

bovino na proporção de $1: 1$, areia lavada, areia lavada + raspa de madeira nas proporções de 3:1, 1:1 e $1: 3$ e raspa de madeira, respectivamente). Esses substratos já tiveram sua eficiência comprovada com outras espécies, a exemplo de Phoenix roebelenii O’Brien, em que, no substrato vermiculita, Iossi et al. (2003) obtiveram plântulas com maior comprimento radicular e baixa ocorrência de raízes secundárias e terciárias. Alexandre et al. (2006) também obtiveram maior comprimento da raiz de plântulas de jabuticaba (Myrciaria spp.) quando utilizaram a vermiculita como substrato.

O maior comprimento das raízes nos substratos com areia foi em função da maior porosidade e aeração, favorecendo, assim, o crescimento das raízes, pelo fato de não haver impedimentos físicos rigorosos que atrapalhem o seu desenvolvimento. Resultados semelhantes foram encontrados por Pacheco et al. (2006), em que os substratos entre e sobre areia proporcionaram melhor desenvolvimento do sistema radicular de plântulas de aroeira-do-sertão (Myracrodruon urundeuva Allemao).

Segundo Avanzato e Cherubini (1993) os substratos com boa retenção de água não se caracterizam somente por causar menor taxa de mortalidade de plantas, mas também pelo aumento no número e no comprimento de raízes.
Quanto ao comprimento da parte aérea (Figura 4), constatou-se que os substratos 5 e 10 (terra vegetal + esterco bovino 1:1 e areia lavada, respectivamente) foram responsáveis pelos maiores valores. Similarmente, Negreiros et al. (2004) constataram a influência de diferentes substratos na formação de porta-enxerto de Annona muricata L e observaram que o esterco em combinação com os outros componentes (esterco de curral, solo, areia e vermiculita $2: 1: 1: 1 \mathrm{v} / \mathrm{v}$ ) e (plantmax ${ }^{\circledR}$, esterco de curral, solo e areia 1:1:1:1 v/v) forneceram as melhores condições de crescimento das mudas. No entanto, Iossi et al. (2003) verificaram maior comprimento da parte aérea de plântulas de Phoenix roebelenii O’Brien quando utilizaram o substrato esfagno e o menos expressivos quando do uso do substrato vermiculita. Em contrapartida, Alexandre et al. (2006) constataram maior comprimento da parte aérea de plântulas de jabuticaba (Myrciaria spp.) quando empregaram o substrato vermiculita. Bezerra et al. (2004) obtiveram maior altura de plântulas quando utilizaram o substrato Plantmax ${ }^{\circledR}$, para moringa (Moringa oleifera Lam.).

Com relação aos dados de massa seca das raízes contidos na Figura 5, verificou-se que nos substratos 4 e 7 (terra vegetal + esterco bovino e terra vegetal + areia, ambos na proporção de 3:1, respectivamente) ocorreram os maiores valores.

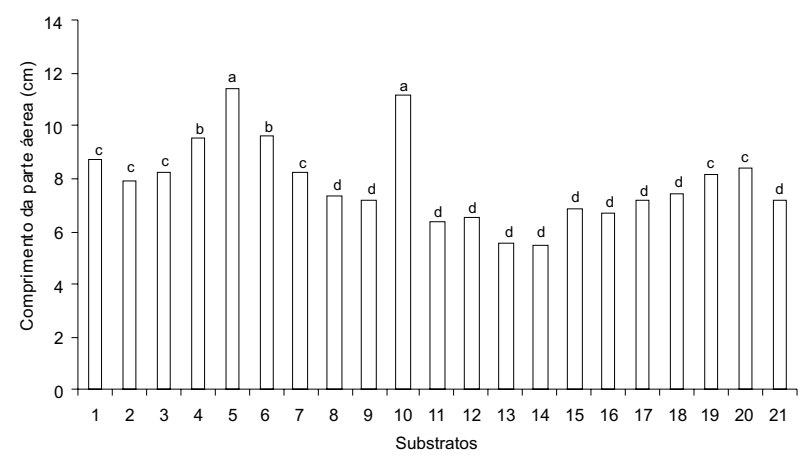

Médias seguidas da mesma letra não diferem estatisticamente entre si, pelo teste de Scott-Knott, $\mathrm{p}<0,05$. F - 7,118**; CV (\%) - 15,084.

Figura 4 - Comprimento da parte aérea de plântulas de juazeiro oriundas de unidades de dispersão semeadas em diferentes substratos.

Figure 4-Length of the aerial part of the Z. joazeiro seedlings originating from dispersion units sown in different substrates.

Revista Árvore, Viçosa-MG, v.34, n.4, p.609-616, 2010 


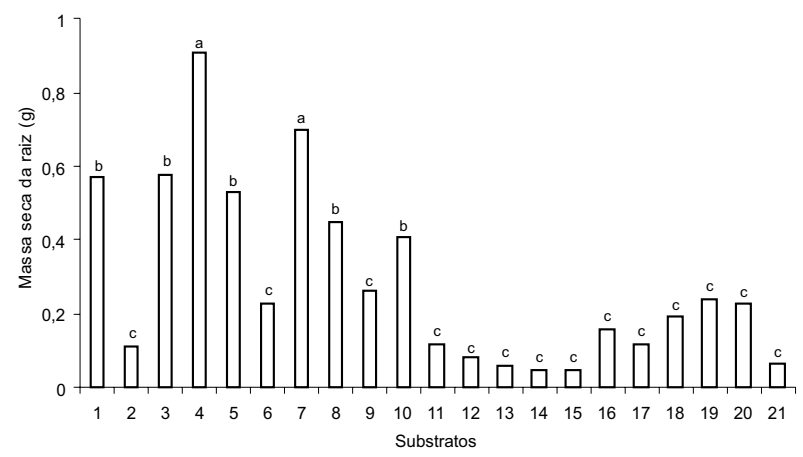

Médias seguidas da mesma letra não diferem estatisticamente entre si, pelo teste de Scott-Knott, p<0,05. F - 5,115**; CV (\%) - 74,298.

Figura 5 - Massa seca das raízes de plântulas de juazeiro oriundas de unidades de dispersão semeadas em diferentes substratos.

Figure 5-Dry mass of roots of Z. joazeiro seedlings originating from dispersion units sown in different substrates.

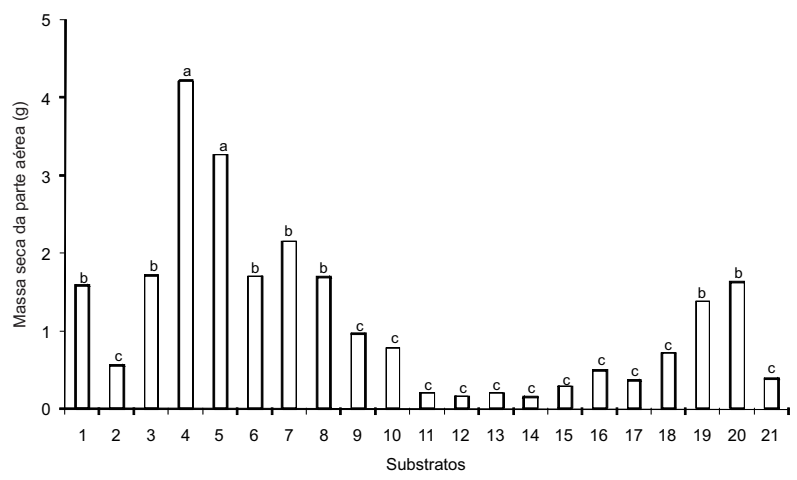

Médias seguidas da mesma letra não diferem estatisticamente entre si, pelo teste de Scott-Knott, $\mathrm{p}<0,05$. F - 7,828**; CV (\%) - 64,997.

Figura 6 - Massa seca da parte aérea de plântulas de juazeiro oriundas de unidades de dispersão semeadas em diferentes substratos.

Figure 6-Dry mass of the aerial part of Z. joazeiro seedlings originating from dispersion units sown in different substrates.

Em trabalhos realizados com Zizyphus joazeiro Mart., Moniz-Brito e Ayala-Osuña (2005) verificaram que o substrato terra vegetal + vermiculita promoveu maior conteúdo de massa seca da parte aérea e do sistema radicular das plântulas.

Conforme dados da Figura 6, constatou-se que os substratos 4 e 5 (terra vegetal + esterco bovino 3:1 e 1:1, respectivamente) apresentaram maior acúmulo de massa seca da parte aérea das plântulas. Tais resultados se devem, provavelmente, a uma melhor condição para emergência mais rápida e uniforme e, consequentemente, maior crescimento inicial das plântulas.

Em trabalhos realizados com sabiá (Mimosa caesalpiniifolia Benth.), Alves et al. (2002) obtiveram os maiores conteúdos de massa seca de plântulas quando as sementes foram colocadas para germinar nos substratos papel, areia e vermiculita. Para sementes de Phoenix roebelenii O’Brien, o substrato vermiculita mostrou-se ineficiente, pois proporcionou menor conteúdo de massa seca da parte aérea (IOSSI et al., 2003). Já em moringa (Moringa oleifera Lam.), Bezerra et al. (2004) obtiveram maior conteúdo de massa seca nas plântulas oriundas de sementes colocadas no substrato Plantmax ${ }^{\circledR}$.

Segundo Wendling et al. (2007), a influência das diferentes características físicas dos substratos depende da variável analisada, em se tratando de erva-doce (Ilex paraguariensis St. Hil.).

\section{CONCLUSÕES}

O substrato mais eficiente para a emergência de plântulas de juazeiro foi terra vegetal.

O maior vigor das unidades de dispersão de juazeiro foi obtido com o substrato terra vegetal + esterco bovino na proporção de 1:1.

\section{REFERÊNCIAS}

ALEXANDRE, R. S. et al. Estádio de maturação dos frutos e substratos na germinação de sementes e desenvolvimento inicial de plântulas de jabuticabeira. Revista Brasileira de Agrociência, v.12, n.2, p.227-230, 2006.

ALVES, E. U. et al. Substratos para testes de emergência de plântulas e vigor de sementes de Erythrina velutina Willd, Fabaceae. Semina: Ciências Agrárias, v.29, n.1, p.17-22, 2008.

ALVES, E. U. et al. Germinação de sementes de Mimosa caesalpiniaefolia Benth. em diferentes substratos e temperaturas. Revista Brasileira de Sementes, v.24, n.1, p.169-178, 2002.

AVANZATO, D.; CHERUBINI, S. Influence of the substrates on the direct rooting of ex vitro, MM106 apple microcuttings. Acta

Horticulturae, n.342, p.297-303, 1993. 
BATAGLiA, O. C.; ABREU, C. A. Análise química de substratos para crescimento de plantas: um novo desafio para cientistas de solo. Boletim Informativo da Sociedade Brasileira de Ciências do Solo, v.26, n.1, p.8-9, 2001.

BEZERRA, A. M. E.; MOMENTÉ, V. G.; MEDEIROS FILHO, S. Germinação de sementes e desenvolvimento de plântulas de moringa (Moringa oleifera Lam.) em função do peso da semente e do tipo de substrato. Horticultura Brasileira., v.22, n.2, p.295-299, 2004.

BORGES, L. C.; FERREIRA, D. F. Poder e taxas de erro tipo i dos testes Scott-Knott, Kukey e StudentNewman-Keuls sob distribuições normal e não normais dos resíduos Revista de Matemática E Estatística, v.21, n.1, p.67-83, 2003.

BRASIL. Ministério da Agricultura e Reforma Agrária. Regras para análise de sementes. Brasília: SNDA/DNDV CLAV, 1992. 365p.

COSTA, A. M. G. et al. Influência de diferentes substratos na formação de porta-enxertos de graviola (Annona muricata L.) em tubetes. In: CONGRESSO BRASILEIRO DE FRUTICULTURA, 17., 2002, Belém. Anais... Belém: SBF, 2002.

FIGLIOLIA, M. B.; OLIVEIRA, E. C.; PIÑARODRIGUES, F. C. M. Análise de sementes. In: AGUIAR, I. B.; PIÑA-RODRIGUES, F. C. M.; FIGLIOLIA, M. B. (Coords.). Sementes florestais tropicais. Brasília: ABRATES, 1993. p.137-174.

GONÇALVES, A. L. Substratos para produção de mudas de plantas ornamentais. In: MINAMI, K. Produção de mudas de alta qualidade em horticultura. São Paulo: T.A. Queiroz, 1995. p.107-115.

GONÇALVES, J. L. M. et al. Produção de mudas de espécies nativas: substratos, nutrição, sombreamento e fertilização. In: GONÇALVES, J. L. M.; BENEDETTI, V. (Eds.). Nutrição e fertilização florestal. Piracicaba: IPEF, 2000. p.310- 350.

IOSSI, E. et al. Efeitos de substratos e temperaturas na germinação de sementes de tamareira-anã (Phoenix roebelenii O’Brien). Revista Brasileira de Sementes, v.25, n.2, p.63-69, 2003.
KÄMPF, A. N. Análise física de substratos para plantas. Boletim Informativo da Sociedade Brasileira de Ciência do Solo, v.26, n.1, p.5-7, 2001.

LAVIOLA, B. G. et al. Efeito de diferentes substratos na germinação e no desenvolvimento inicial de jiloeiro (Solanum gilo Raddi), cultivar verde claro. Ciência e Agrotecnologia, v.30, n.3, p.415-421, 2006.

LORENZI, H. Árvores brasileiras: manual de identificação e cultivo de plantas arbóreas nativas do Brasil. 2.ed. Nova Odessa: Instituto Plantarum, 2002. 368p.

MACHADO, C. F. et al. Metodologia para a condução do teste de germinação em sementes de ipê-amarelo (Tabebuia serratifolia (Vahl) Nicholson). Cerne, v.8, n.2, p.17-25, 2002.

MAGUIRE, J. D. Speed of germination aid in selection and evaluation for seedling emergence and vigor. Crop Science, v.2, n.2, p.176-177, 1962.

MELO, A. C. G. Efeitos de recipientes e substratos no comportamento silvicultural de plantas de Eucalyptus urophylla S.T. Blake. 1989. 80f. Dissertação (Mestrado em Ciências Florestais) - Escola Superior de Agricultura Luiz de Queiroz, Piracicaba, 1989.

MENDES, B. V. Juazeiro (Zizyphus joazeiro Mart.): símbolo da resistência das plantas das caatingas. Mossoró: Fundação Vingt-Un Rosado/ ETFERN-UNED, 1996. 24p. (Coleção

Mossoroense, 168).

MONIZ-BRITO K. L.; AYALA-OSUÑA, J. T. Influência de diferentes substratos na germinação de sementes de Ziziphus joazeiro Mart., Rhamnaceae. Sitientibus Série Ciências Biologicas, v.5, n.2, p.63-67, 2005.

NEGREIROS, J. R. S. et al. Influência de substratos na formação de porta-enxerto de gravioleira (Annona muricata L.). Ciência e Agrotecnologia, v.28, n.3, p.530-536, 2004.

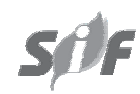

Revista Árvore, Viçosa-MG, v.34, n.4, p.609-616, 2010 
NOGUEIRA, R. J. M. C.; ALBUQUERQUE, M. B.; SILVA JUNIOR, J. F. Efeito do substrato na emergência, crescimento e comportamento estomático em plântulas de mangabeira.

Revista Brasileira de Fruticultura, v.25, n.1, p.15-18, 2003.

OLIVEIRA, I. V. M.; CAVALCANTE, I. H. L.; MARTINS, A. B. G. Influência do substrato na emergência de plântulas de sapota preta.

Caatinga, v.19, n.4, p.383-386, 2006.

ORLANDER, G; DUE, K. Location of hydraulic resistante in the soil-plant pathway in seedling of Pinus silvesrtris L. grown in peat. Canadian Journal of Forest Research, v.16, n.1, p.115-116, 1986.

PACHECO, M. V. et al. Efeito de temperaturas e substratos na germinação de sementes de Myracrodruon urundeuva Fr. All. (Anacardiaceae). Revista Árvore, v.30, n.3, p.359-367, 2006.

POPINIGIS, F. Fisiologia da semente. 2.ed. Brasília: ABRATES, 1985. 298p.

SANTOS, D. S. B. et al. Efeito do substrato e profundidade de semeadura na emergência e desenvolvimento de plântulas de sabiá. Revista

Brasileira de Sementes, v.16, n.1, p.50-53, 1994.

SCALON, S. P. Q. et al. Efeito do álcool e substrato na germinação de sementes de sibipiruna (Caesalpinia pelthophoroides Benth.) colhidas no chão e retiradas da vagem. Ciência e Agrotecnologia, v.27, n.2, p.389-392, 2003.
SCHMITZ, J. A. K.; SOUZA, P. V. D.; KAMP, A. N. Propriedades químicas e físicas de substratos de origem mineral e orgânica para o cultivo de mudas em recipientes. Ciência Rural, v.32, n.6, p.937-944, 2002.

SEDIYAMA, M. A. N. et al. Nutrientes em compostos orgânicos de resíduos vegetais e dejetos de suínos. Scientia Agrícola, v.57, n.1, p.185-189, 2000.

SOUZA, E. R. B. et al. Emergência e crescimento de cagaita (Eugenia dysenterica DC em função do tipo e do volume de substratos. Pesquisa Agropecuária Tropical, v.31, n.2, p.89-95, 2001.

SOUZA, F. X. Materiais para a formação de substratos na produção de mudas e cultivo de plantas envasadas. Fortaleza: Embrapa Agroindústria Tropical, 2001. 21p. (Documento, 43).

SOUZA, M. Nutrição e adubação para produzir mudas de frutíferas. Informe Agropecuário, v.9, n.102, p.40-43, 1983.

SPURR, S. H.; BARNES, B. V. Forest ecology. New York: The Ronald Press, 1973. 571p.

WENDLING, I.; GUASTALA, D.; DEDECEK, R. Características físicas e químicas de substratos para produção de mudas de Ilex paraguariensis St. Hil. Revista Árvore, v.31, n.2, p.209-220, 2007. 